\title{
Cultural factors in the adoption and use of GSS
}

\author{
R.M. Davison \\ Lecturer \\ Department of Information Systems, City University of Hong Kong \\ Tat Chee Avenue, Kowloon, Hong Kong \\ Tel: (852) 2788-7534; Fax: (852) 2788-8694; \\ Email: isrobert@cityu.edu.hk \\ E. Jordan \\ Associate Professor in Management \\ Macquarie Graduate School of Management \\ Macquarie University, NSW 2109, Australia \\ Tel: (61) 2850 9041; Fax: (61) 28509019 \\ Email: Ernest.Jordan@mq.edu.au
}

\begin{abstract}
In this research, we set the agenda for an analysis of organisations that are, or are about to, go through the process of becoming more international by upgrading their interactive communication technologies with products such as Group Support Systems (GSS). The various impacts that national culture can have on an organisation's use and adoption of GSS are identified and illustrated with examples. Two complementary models of organisational structure are also presented and analysed from the GSS perspective. The significant issues which a GSS facilitator/implementer should be aware of in different cultural environments are pointed out.
\end{abstract}

\section{Keywords}

GSS, national culture, organisational structure 


\section{CULTURE AND INFORMATION}

Inside working organisations, as in all areas of human activity, the behaviour of people is affected by the values and attitudes that they hold. The collective patterns of behaviour are important parts of the culture of the work-group or nation, which form a backdrop against which values and attitudes are in turn developed. This cycle is expressed succinctly in Figure 1, taken from Adler (1986).

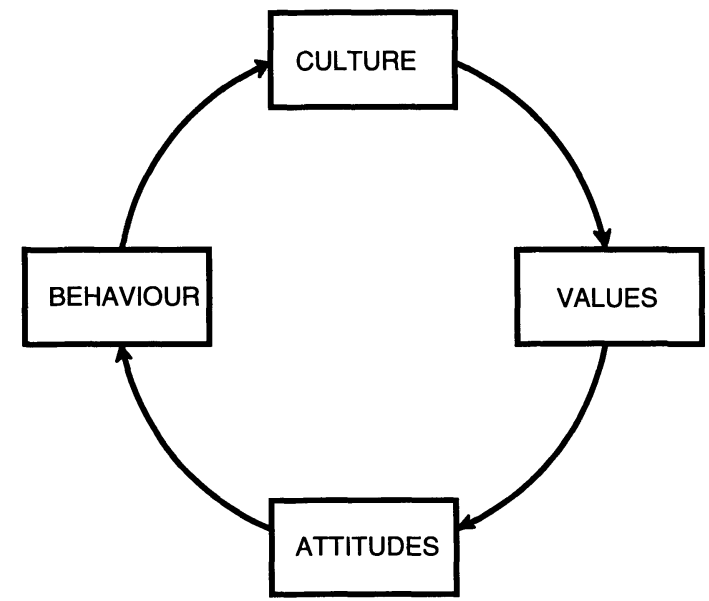

Figure 1 The influence of culture on behaviour.

Data only becomes information when it is interpreted by a person, and this interpretation of necessity takes place against the backdrop of the individual's culture (Tricker, 1988). In decisionmaking information is a prerequisite (Simon, 1960) and the decision-making process is deeply affected by culture (Adler, 1986). Thus the meaning of information and effectiveness of an information system can vary substantially in different cultures. National cultures have long been associated with differences in the organising and operating of businesses and, more recently, cultures specific to organisations have been studied.

In a wider sense, Ouchi (1981) signalled the importance of national values as they impact upon corporate culture. He established a clear link from Japanese national culture to the corporate cultures of major organisations and then to the outstanding success of Japanese business. His interest was the possibility of transferring or creating Japanese-like corporate values (and hence culture) in American industry in order to generate similar successes. He also reported that some American organisations already had cultures much like Japanese organisations and, he argued, this was significant in their success.

We now examine two alternative theoretical frameworks for culture that can be used to examine information, and specifically the way it is used in a GSS, in an organisational setting. Following this, we discuss how organisational culture and national culture can interact so as to produce a more or less favourable environment for GSS implementation and use. A conclusion follows with a summary of the benefits and dangers of GSS implementation and use in organisations in different cultural settings. 
From the viewpoint of Williamson (1975), organisations come into their very existence because of information. The uncertainty of the marketplace, characterised by information about transactions, drives individuals into forming or joining organisations, while the continuing uncertainty in the environment of the organisation leads it to changes in its strategy and structure. This view reduces all business activity to transactions between individuals and groups, with information as the controlling resource. While such a simple and powerful mechanism is attractive to some information technologists, giving primacy to information and economic activity, it is too simplistic to deal with the real social, psychological and political settings of most organisations. It is an example of what Bolman and Deal (1991) term the 'structural frame' of organisations and does not immediately link to the other frames - the human resource, political and cultural.

Williamson's (1975) ideas were extended by Boisot (1987). Boisot's aim is to incorporate a cultural perspective into the transactional costs approach. He looks at information in organisations through two attributes of the information, its 'codification' and 'diffusion', and the ways that these two dimensions affect information transactions:

- codification the degree of formal representation;

- diffusion the degree of spread throughout the population.

This builds on Williamson (1975) by realising that the effect of internalising the transaction within the organisation is to reduce its diffusion. Thus the diffused information in the marketplace becomes undiffused in the bureaucracy.

Dichotomising organisational forms based upon the two dimensions of codification and diffusion leads to the categories shown in Figure 2. Codified information is commonplace in formal business settings and so gives rise to the major structural forms. If information is centralised (i.e. undiffused) a bureaucracy is the form, while if it is widely distributed a market is in effect. Bureaucracies correspond closely to Williamson's description of hierarchies. The additional dimension of codification - in particular the absence of codification - produces fiefs and clans. A fief is controlled by an individual in whose mind most of the real ('soft') information resides while a clan has diffused but uncodified information, such as in a group of like-minded professionals.

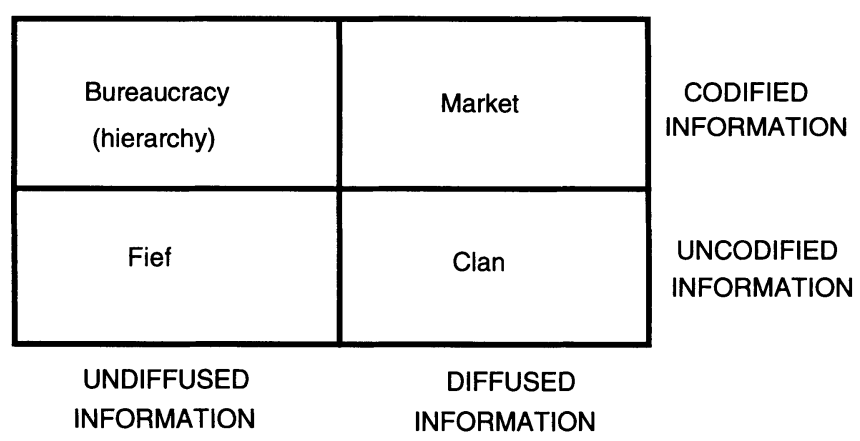

Figure 2 Organisation forms with information codification and diffusion (Boisot, 1987). 
It is useful to analyse this model of information codification and diffusion from the perspective of GSS 'forces'. GSS are acknowledged as systems that provide structure to information and to the context in which that information is being used. In this way, the structuration enabled through GSS use parallels the codification of information present in bureaucracies and markets. Such codification is not present in fiefs and clans. Consequently, use of a GSS in a fief or clan context would set in motion forces to structure and codify information - processes that might well be most unwelcome to the fief and clan chiefs. These individuals are able to maintain their control (and power which we will discuss later) over their organisations through a lack of formal structuring. To replace the lack of structure with structure could well be anathema to them as it would have the potential to diminish, even remove, their means of control.

GSS, and other forms of groupware such as email, are also acknowledged as distributors and disseminators of information. The ability of an individual to send a single email message to a list of users greatly enhances the diffusion of information. Similar results are obtainable through the use of a GSS - whatever an individual types into the system will, sooner or later, be seen by all individuals participating (or authorised to participate) in that session. This feature of a GSS parallels the diffusion of information seen in clans and markets. In a perfect market, all information is known to all individuals simultaneously. In a clan, information is shared freely among the clan members perhaps members of a board or committee where there is little variation in status (which we will also discuss later). On the other hand, bureaucracies and fiefs do not have the same level of diffusion of information. Consequently, use of a GSS in a fief or bureaucracy will set in motion forces that seek to diffuse the existing centralised information. Just as with the issue of information codification, information diffusion may be unacceptable to the chiefs of bureaucracies and fiefs and for similar reasons: when information is (more) freely available, authority that stems from sole (or restricted) possession of information is reduced.

Viewing the codification/diffusion dichotomy from this stance, we can see that, assuming the maintenance of the status quo to be paramount, GSS use is practical in markets, has both advantages and disadvantages in bureaucracies and clans, and is contraindicated in fiefs.

\section{HOFSTEDE'S DIMENSIONS}

Hofstede's (1980) massive study of national culture has since been replicated and used extensively. Its authority is enhanced by its predictive ability and its synthesis of previous partial results. Hofstede collected 117000 questionnaires from 88000 respondents in 66 countries, all employees of the same multinational corporation, which enabled employees in different countries to be matched. Four dimensions of national culture were found and index scores developed for each of 40 countries (Hofstede, 1980).

power distance (PDI) - the degree of inequality of power between a person at a higher level and a person at a lower level, (being subservient to the boss),

uncertainty avoidance (UAV) - the extent to which future possibilities are defended against or accepted (not facing the future or trying to organise it),

individualism (IDV) - the relative importance of individual goals compared with group or collective goals (looking after oneself),

masculinity (MAS) - the extent to which the goals of men dominate those of women (assertion - nurturance). 
Power distance and individualism are strongly negatively correlated and represented only a single factor in a confirmatory factor analysis, yet Hofstede argues that they are conceptually different and were independently developed as indices with reference to extensive literature bases. Uncertainty avoidance also shows weaker correlations, positive with power distance and negative with individualism. Thus these dimensions are not orthogonal but nevertheless refer to four 'universal problems of mankind' (Hofstede, 1980).

Uncertainty avoidance is the domain of information systems, including group support systems. It is noteworthy, and perhaps paradoxical, that the significant developments in this domain have come from countries that Hofstede found to have low levels of uncertainty avoidance. In these countries, for example the USA, UK, the Netherlands and Denmark, the future is accepted as having much uncertainty with which one must live. In countries with much higher levels of uncertainty avoidance (Greece, Portugal, Mexico, Argentina) unfavourable outcomes must be controlled against. As we have already noted, GSS acts to promote information codification and structuring. These activities are typical of the approach to uncertainty undertaken by organisations in countries with high UAV scores, though organisations in countries with low UAV scores also make considerable use of them.

The second of Hofstede's dimensions that is critical to the GSS facilitator, designer or implementer is power distance, which allows for varying relationships between superiors and subordinates in organisations. The 'spirit' (DeSanctis and Poole, 1994) of GSS is that it promotes the democratic diffusion of information and decentralisation of decision making. If the boss is powerful and cannot be contradicted, then a GSS may be seen as unacceptable, 'insubordinate' and possibly threatening. This issue is best illustrated with reference to a short, and perhaps apocryphal, story:

In a GSS session organised for the army, a group of soldiers of varying ranks, including at least one General who is the convenor of the meeting, are discussing what is good and bad with current operational practices in the army. At some stage in the meeting, a participant (of unknown identity and rank) makes a comment which evidently displeases the convening general. He gets to his feet and demands to know who made this comment, saying that it is absolutely not true. The answer not forthcoming, the general cancels the meeting and all subsequent meetings.

In this case, the General is unable to accept some (unrevealed) information which he believes is untrue. The system has enabled the dissemination of information which may constitute a threat or just be insubordinate to the general and/or his position. Unable to tolerate this, the General, as convenor, cancels the meeting and thereby eliminates use of the technology responsible for the threat to his position.

A third dimension of importance to the GSS facilitator is Individualism/Collectivism. If a culture is group-oriented, then one might suppose that use of GSS (with its focus on group work) would be more suitable than in an individual-oriented culture. However, this is not necessarily the case. In an individual-oriented culture, GSS will certainly act as a force towards group work inasmuch as the members of the group are required to work together so as to achieve a result that is likely to be acceptable to all group members. The provision of anonymity in the intergroup communications allows members to submit ideas without revealing their identity, but, as the literature has shown, this increases not only the task focus of the meeting (Poole et al., 1991), but also the equality of participation (Sproull and Kiesler, 1986). When, on the other hand, the culture is group-oriented, the use of a GSS that incorporates anonymous communications can have dysfunctional effects, as 
illustrated by a study undertaken in Singapore and the USA (Watson et al., 1994). In this study, it was found that some features of GSS were not compatible with Singaporean notions of correct group behaviour. These notions include the fact that public dissent is to be avoided, whereas consensus is to be encouraged. Consensus does not necessarily correspond to Senator Fulbright's 'genuine reconciliation of differences' (Tripp, 1976), but more to the notion that members of society have a social obligation to conform to rules that place national interests higher those of individuals. Therefore, when a GSS (designed in accordance with North American cultural norms) was used in a Singaporean setting, certain individuals were able to use anonymous communications - a feature of GSS that is not compatible with Singaporean social norms - to criticise other members of the group (a culturally discouraged behaviour). Watson et al. (1994) suggest that 'anonymity should be a switchable feature' so as to permit the GSS facilitator the opportunity to make communications identified if this is culturally appropriate or necessary. They also hypothesise that GSS might be more suitable in a distributed, asynchronous setting, where identification of individuals is no longer an issue and the critical aspects of communication that might threaten group harmony would be removed.

Further to Boisot's (1987) model, Hofstede specifies an underlying 'implicit model' that describes the nature of interactions taking place between people in (un)codified and (un)diffused situations, that is, the types of transactions. The names for the various elements of the implicit model correspond closely to Boisot's four forms. We can then see some form of association between Hofstede's uncertainty avoidance and power distance and Boisot's codification and diffusion of information. We will discuss the role of Hofstede's individualism dimension later. Incorporating the implicit model in Boisot's model of organisational forms yields a composite framework, shown in Figure 3, that links information and structure to culture.

\begin{tabular}{|c|c|c|c|}
\hline & HOFS & TEDE & \\
\hline HOFSTEDE & & & BOISOT \\
\hline Low & $\begin{array}{l}\text { IM: well-oiled machine } \\
\text { B: bureaucracy }\end{array}$ & $\begin{array}{l}\text { IM: market } \\
\text { B: market }\end{array}$ & $\begin{array}{l}\text { Codified } \\
\text { Information }\end{array}$ \\
\hline $\begin{array}{l}\text { High } \\
\text { Power distance }\end{array}$ & $\begin{array}{l}\text { IM: pyramid } \\
\text { B: fief }\end{array}$ & $\begin{array}{l}\text { IM: family } \\
\text { B: clan }\end{array}$ & $\begin{array}{l}\text { Uncodified } \\
\text { Information }\end{array}$ \\
\hline Key & & & \\
\hline IM - implicit model & & & \\
\hline & Undiffused information & Diffused information & \\
\hline
\end{tabular}

Figure 3 Power distance and uncertainty avoidance impact on organisational types.

The figure has been presented so that it is directly comparable with Boisot's information codification and diffusion model (Figure 2) with Boisot's labels added as well as the 'implicit model' field. This shows power distance and uncertainty avoidance as empirically-established variables that explain more effectively the variation found by Boisot (1987). The information codification and diffusion dimensions augment the power distance and uncertainty avoidance ones, establishing configurations of culture, information and organisation that are self-reinforcing.

Hofstede (1980) goes further, dichotomising national cultures on the basis of uncertainty avoidance and power distance. Thus, for example, English speaking (Anglophone) countries, 
Scandinavia and the Netherlands have low uncertainty avoidance and low power distance whereas Mediterranean countries score high on both. These are presented in Figure 4 along with Boisot's categorisation. This is not intended to say that, for example, all Finnish organisations will be bureaucracies; rather, under given circumstances, a Finnish organisation is more likely to be structured as a bureaucracy.

\section{HOFSTEDE}

High uncertainty avoidance Low uncertainty avoidance

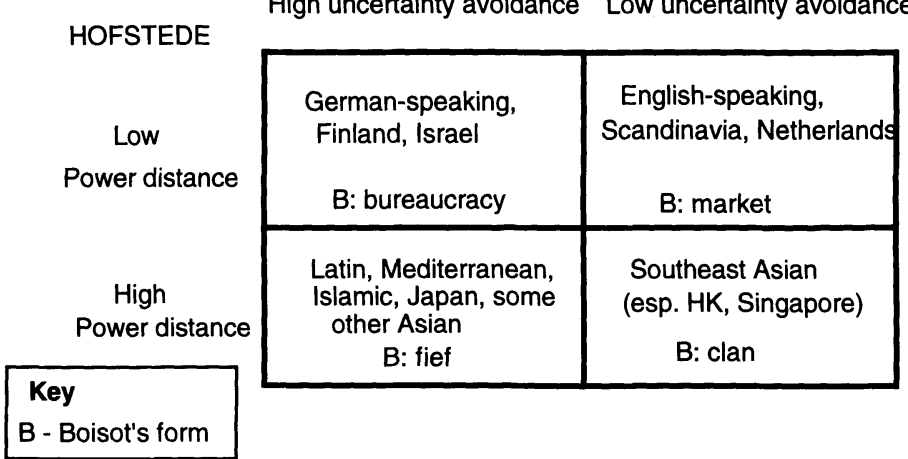

Figure 4 Association of power distance and uncertainty avoidance with national culture.

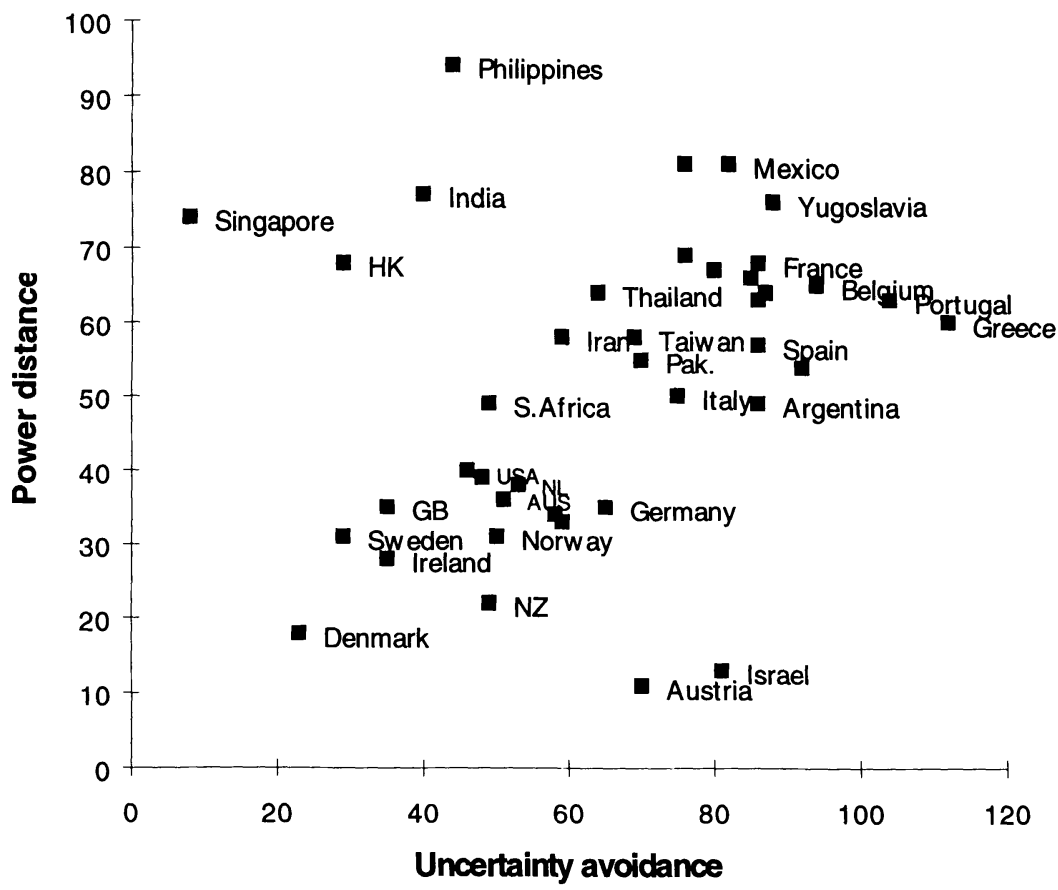

Figure 5 National power distance and uncertainty avoidance values (Hofstede, 1980). 
Hofstede (1980) produces a scatter diagram of uncertainty avoidance against power distance, which shows the distribution of the national cultures. This was used in his categorisation of countries that is shown above. This material is widely quoted in the literature and is redrawn in Figure 5 above.

\section{DISCUSSION}

It is useful to analyse the compound Hofstede and Boisot model presented in Figure 3 from two different but complementary GSS viewpoints: ease of implementation and necessity. These two views are, arguably, of vital importance to the GSS facilitator, designer or implementer, since identification of where a particular group, organisation or culture lies in respect of these factors may determine if and how GSS implementation and use should be approached.

In the idealised market structure of Boisot (1987), with codified and diffused information, low power distance and low uncertainty avoidance, it might seem that a GSS is unnecessary. If information is freely shared around, is structured and there exists a climate where uncertainty needs not to be guarded against, why implement a system that seeks to promote information structuring, sharing of information and coping with uncertainty? Furthermore, given the prevalent low uncertainty avoidance, some managers may be sceptical of the benefits accruing from GSS, thinking that the system will not be able to change anything. This is, of course, a view at the low extreme of the uncertainty avoidance continuum. Nonetheless, it is ironical that it is in the market context that GSS are most widely used. This is supported by Figure 4, which indicates that it is the Anglophone countries, The Netherlands and Scandinavia that belong to this quadrant of the compound model countries which we know to make considerable use of GSS technologies. While, GSS may not be strictly necessary in the perfect market, it should be easy to implement GSS in a context of low power distance, since there is no boss to threaten. However, those involved in the implementation process should ensure sufficient user participation so as to avoid accusations of authoritarianism - a behaviour disapproved of in a low power difference culture.

In the well-oiled machine or bureaucracy, power distance is low, information is codified, uncertainty avoidance is high and information is undiffused. The low power distance will improve the chances of successful GSS implementation, while the need to avoid uncertainty will be facilitated through a GSS's structuration of the decision making process, aided by the existing codified information. There exists some danger that the output of the GSS will be believed to too great an extent, i.e. too much faith will be placed in its accuracy. This stems from the perceived need to avoid uncertainty, and so the desire to make use of any and every system to help in the achievement of that goal. As described above, the GSS will act as a force in favour of information diffusion. This is perhaps the only warning note, since opposition to such diffusion could hinder the implementation and use of the system.

In the family or clan, information is uncodified but diffused, power distance is high and uncertainty avoidance is low. The high power distance may hinder the implementation of GSS, particularly if the system is seen as a threat to existing norms, for a GSS is recognised as a force for decentralisation of authority and consensual (participatory) decision making. This was illustrated above in the Singapore example. Although information is not codified in the typical clan organisation, the combination of low uncertainty avoidance and high information diffusion suggest that the forces of structuration and information diffusion will not be required in this context.

Hong Kong also lies within this 'clan' quadrant of the compound model (cf. Figure 4). The location of Hong Kong on the scattergram is, like all other countries, dependent on the values obtained for a range of employees at IBM in the late 1970s when Hofstede's (1980) survey was conducted. A 
unique feature of Hong Kong's management structure is that it is not national culturally homogeneous. Rather, there are many managers who are not Hong Kong Chinese, including those from Europe and North America, as well as elsewhere around the world. This point is made so as to illustrate the limitations associated with relying on a single source of information for clues to the successful implementation of GSS. It will always be essential to conduct a detailed review of an organisation, and its information and organisation needs and norms, before deciding if and how to implement GSS.

Finally, the fief is an organisation which has uncodified and undiffused information, high power distance and high uncertainty avoidance. GSS implementation in such a context will not be easy due to the high power distance. However, there are likely to be other forms of resistance connected with the push factors inherent in the spirit of GSS. As acknowledged already, GSS act as a force towards information dissemination. This is not a feature of fief organisations where the chief holds all information and does not tolerate much criticism. Furthermore, GSS act to decentralise decision making to a group of meeting participants. This too may be anathema to the authoritarian chief who needs to retain his central authority over decision making in order to maintain control. The fact that a GSS would assist in the drive to avoid uncertainty is perhaps the only positive factor to a GSS implementation, when seen from the viewpoint of the status quo. Analysed according to the 'spirit' of GSS, a major worry about GSS implementation and use in a fief is the danger that the system would be used for purposes other than those intended by the software's developers. Naturally, users are free to utilise the software in any way they choose, as we have already illustrated. One foreseeable problem in the fief is the pressure that might be placed 'upon the information providers to generate only the information that is acceptable' (Jordan, 1994) to the chief. Subordinates would be unlikely to disagree with this order and as a result, the Group Support System would become an Individual Confirmation System - the GSS could be used most effectively to show that all subordinates thoroughly approved of (or at least complied with) whatever course of action the chief decided upon. To object, even anonymously, could result in the abandoning of the software.

We now turn to Individualism/Collectivism. Individualism is often associated with Western countries and cultures, while Oriental societies and cultures are seen as collectivist. This is not the most helpful of classifications, as much of the world does not easily fit into the West-East bipolar model. Where, for example, should Australia and Papua New Guinea lie? They are geographical neighbours, but at opposite ends of cultural, social and developmental spectra.

Hofstede's (1980) own analysis places the Anglophone and Western European countries at the high end of the Individualism index, while countries at the low end can be found in South America and South East Asia (Hong Kong, Singapore, Taiwan and Thailand among them). We already know that power distance and individualism tend to be inversely correlated and we have shown that it is likely to be more difficult to implement GSS in high power distance contexts. Most of the literature on GSS both originates in the market organisational culture and describes implementations in that culture, where individualism tends to be the norm. This is not to say that those implementations were always successful, and to be sure there are a plethora of other factors influencing the successfulness of GSS implementation. However, while GSS initiate forces to increase information dissemination and to decentralise decision making, they also, and not surprisingly, initiate a push towards group based work. For an individualist culture, this is, perhaps, a new mode of work where individuals have to cooperate with each other as members of a team so as to achieve a common goal. The culture of low power distance associated with high individualism still exists of course. By way of contrast, in a collectivist culture, where high power distance is the norm, group work is already institutionalised. The introduction of a GSS into such a culture 'is a discontinuity in a group's life' (Watson et al.). If a group is forced to accept the new form of information exchange, a form developed in an entirely 
different cultural environment, it is likely that it will be rejected or else used in ways not intended by the software developers, as was the case in the Singapore example we described above. Individualism, thus, need not be a barrier to GSS use. Paradoxically, collectivism may raise more barriers and groups which are formed in collectivist cultures may need to make more modifications to a GSS in order to use it effectively.

\section{$5 \quad$ CONCLUSIONS}

The nature and role of information is central to decision making, and, just as emphatically, culture has a critical impact on the design, selection and use of group support systems. The first step for the GSS facilitator, designer or implementer has to be a study of the organisation's culture, and in the case of transnational and multinational systems, the national cultures involved. Such a study will give warnings of modes of information handling, supervision and control that will be directly related to the introduction of a GSS or any other information system. We suggest that such an investigation could start with the questionnaire of Hofstede (1980) and then use some of the above analyses.

\subsection{National culture}

Hofstede's dimensions of power distance, uncertainty avoidance and individualism may be of great significance to the GSS facilitator, designer and implementer, especially if the values are extreme, that is, very high or very low. Such extreme values can lead to systematic rejection of information or processes that do not conform to acceptable standards or norms. Other extreme values may lead to over-reliance on the same information or processes to the detriment of the decision making processes in the organisation. By being aware of the cultural and organisational environment, the GSS designer may be able to foresee some of the benefits and dangers that use of a GSS might entail. These benefits and dangers are most critical for a GSS facilitator or implementer who is not a national of the country where implementation or use is taking place. The benefits and dangers can be summarised briefly as:

- If uncertainty avoidance is strong then a GSS will help to structure information and the decision making process. However, there is a risk of overdependence on the output of the GSS.

- If uncertainty avoidance is weak, GSS may be superfluous since it will try to provide structure when none is required. Moreover, fatalism leads to scepticism about GSS usefulness and possible resistance from users.

- If power distance is large then the boss may disagree with the GSS and the boss is right. GSS implementation will be very difficult, though the boss may try to subvert the original spirit of the GSS so as to create support for his own objectives irrespective of reality.

- If power distance is small, it will be easy to implement GSS, but authoritative approaches will be risky as they may alienate the users.

- If individualism is high, GSS use will require the adoption of new work practices - team work - but is likely to result in increased task focus and decreased process losses.

- If individualism is low, GSS may disrupt existing group work practices. Individuals may adapt some features of the GSS so as to indulge in culturally unacceptable behaviour. 


\subsection{System development and change processes: moving to the IOF}

As a consequence of their increasingly widespread use in organisations, GSS are implicitly associated with organisational change. In the future, we can expect to encounter transnational and multinational organisations and meetings with increased frequency. The International Office of the Future may not be recognisable in terms of the cultural values we are familiar with, yet how successful will that office of the future be? We should be deeply concerned about the manner in which national and organisational cultures will influence organisational change - a change that must take place en route to the office of the future, if only to accommodate the multifarious new environments - cultural, social and human - that will need to be incorporated into that office. Thus far, there has been precious little research into how multicultural, multilingual offices might function. How successful such transitions - to the IOF - will be depends to a considerable degree on the extent to which organisations face up to and attempt to reconcile the cultural differences between the various component parts of their present and future organisation. The benefits and dangers we have highlighted are just a few of the issues that demand attention. Much more work remains to be done in trying to put all the pieces of this cultural jigsaw together in the right way. However, as Hofstede (1980) has pointed out, we should also realise, aculturally, that there is no one correct solution that can apply to all organisational, cultural or social problems. Each context, each problem has its own jigsaw that has to be solved separately. What we have attempted to do in this paper is to suggest a method for approaching the riddle of how to solve the jigsaw puzzle, not solve the puzzle itself.

\section{REFERENCES}

Adler, N.J. (1986) International dimensions of organizational behavior. Kent Publishing Co., Boston, Mass.

Boisot, M. (1987) Information and organizations: the manager as anthropologist. Fontana, London.

Boisot, M. and Child, J. (1988) The iron law of fiefs: bureaucratic failure and the problems of governance in the Chinese economic reforms. Administrative Science Quarterly, 33, 507-527.

Bolman, L.G. and Deal, T.E. (1991) Reframing organizations: artistry, choice and leadership. Jossey-Bass, San Francisco, CA.

DeSanctis, G.L. and Poole, M.S. (1994) Capturing the complexity in advanced technology use: adaptative structuration theory, Organization Science, 5, 2, 121-147.

Hofstede, G. (1980) Culture's consequences: international differences in work-related values. Sage, Beverly Hills, CA.

Jordan, E. (1994) National and organisational culture: their use in information systems design, Working Paper WP94/08, Department of Information Systems, City Polytechnic of Hong Kong.

Ouchi, W.G. (1981) Theory Z: how American business can meet the Japanese challenge. Avon, New York, NY.

Poole, M.S., Holmes, M. and DeSanctis, G.L. (1991) Conflict management in a computer-supported meeting environment, Management Science, 37, 8, 926-953.

Simon, H.A. (1960) The New Science of Management Decision. Harper and Row, New York, NY.

Sproull, L. and Kiesler, S. (1986) Reducing social context cues: electronic mail in organisational communication, Management Science, 32, 11, 1492-1512. 
Tricker, R.I. (1988) Information resource management - a cross-cultural perspective. Information and Management, 15, 37-46.

Tripp, R.T. (1976) The international thesaurus of quotations, Penguin: Harmondsworth.

Watson, R.T., Ho, T.H. and Raman, K.S. (1994) Culture: a fourth dimension of group support systems research, Communications of the ACM, 37, 10, 44-55.

Williamson, O.E. (1975) Markets and hierarchies: analysis and antitrust implications. Free Press, New York, NY.

\section{BIOGRAPHY}

Robert Davison is currently a Lecturer and a $\mathrm{PhD}$ student at the Department of Information Systems, City University of Hong Kong where he is investigating how GSS can be applied in the Hong Kong environment and culture. He also maintains research interests in cross-cultural psychology, the ethical use of IT and computational linguistics. His training was as a Slavic linguist before turning to IS in the early 1990s.

Dr Ernest Jordan had some ten years experience in the development of information systems in commerce and industry before entering the academic world. He has just returned to Australia after eight years at City University of Hong Kong, where he helped in the establishment of the information systems department and its bachelor's and master's degree programmes. His research interests include the strategic aspects of information technology, executive information systems, and enhancing teamwork in information systems development. He has published in the International Journal of Information Management, Information Systems Journal, Journal of Strategic Information Systems, and the Australian Computer Journal. 